Article

\title{
Circulating Tumor Cell Assay to Non-Invasively Evaluate PD- L1 and Other Therapeutic Targets in Multiple Cancers
}

\author{
Raymond Page ${ }^{1}$, Darshana Patil ${ }^{1}$, Dadasaheb Akolkar ${ }^{1}$, Sudha S Murthy' ${ }^{1}$, Kiran Bendale ${ }^{1}$, Revati Patil ${ }^{1}$, Pradeep \\ Fulmalii, Pooja Fulmali ${ }^{1}$, Archana Adhavi, Sneha Puranik ${ }^{1}$, Sachin Apurwa ${ }^{1}$, Vineet Datta ${ }^{1}$, Chirantan Bose ${ }^{1}$, Stefan \\ Schuster ${ }^{2}$, Jinumary John ${ }^{1 *}$, Ajay Srinivasan ${ }^{1}$, Rajan Datar ${ }^{1}$
}

1 Datar Cancer Genetics, Nasik, India; rpage@datarpgx.com (R.P.) drdarshanap@datarpgx.com (D.P.); dadasaheb.akolkar@datarpgx.com (D.A.); udha.murthy@datarpgx.org (S.M.); kiran.bendale@datarpgx.org (K.B.); drrevatipatil@datarpgx.org (R.P.); pradipfulmali@datarpgx.org (P.F.); pooja.fulmali@datarpgx.org (P.F.); archana.adhav7@gmail.com (A.A); sneha.puranik@datarpgx.org (S.P.); sachinapurwa@datarpgx.org (S.A.); drvineetdatta@datarpgx.com (V.D.); chirantan.bose@datarpgx.org (C.B.); drstefanschuster@datarpgx.com (S.S); jinumary@datarpgx.org (J.J.); ajays@datarpgx.org (A.S.); rajandatar@datarpgx.com (R.D.)

2 Datar Cancer Genetics Europe GmbH, Eckersdorf, Germany

* Correspondence: jinumary@datarpgx.org; Tel: 91-0253-6690803

Simple Summary: Selection of molecularly targeted anti-cancer treatments with monoclonal antibodies as well as with small molecules is often informed by immuno-histochemical confirmation of target marker expression on tumor tissue that is obtained by invasive biopsy. However, tissue biopsies are resource-intensive with procedural risks and limitations, and repeat sampling may not be possible following tissue insufficiency. Therefore, a non-invasive alternative for determining the presence of molecular markers in cancer patient sample, for selection of targeted anti-cancer drugs is warranted. Here, we describe the analytical and clinical performance characteristics of a Circulating Tumor Cell (CTC)-based test to determine the presence of PD-L1, ER, PR and HER2 in patients with solid organ tumors for selection of respective targeted therapy. The performance characteristics of the test support its clinical suitability and applicability.

\begin{abstract}
Biomarker directed selection of targeted anti-neoplastic agents such as immune checkpoint inhibitors, small molecule inhibitors and monoclonal antibodies form an important aspect of cancer treatment. Immunohistochemistry (IHC) analysis of the tumor tissue is the method of choice to evaluate the presence of these biomarkers. However, a significant barrier to biomarker testing on tissue is the availability of an adequate amount of tissue and need for repetitive sampling due to tumor evolution. Also, tumor tissue testing is not immune to inter- and intra-tumor heterogeneity. We describe the analytical and clinical validation of a Circulating Tumor Cell (CTC) assay to accurately assess the presence of PD-L1 22C3 and PD-L1 28.8, ER, PR and HER2, from patients with solid tumors to guide the choice of suitable targeted therapies. Analytically, the test has high sensitivity, specificity, linearity and precision. Based on a blinded case control study, the clinical sensitivity and specificity for PD-L1 (22C3 and 28.8) was determined to be $90 \%$ and $100 \%$ respectively. The clinical sensitivity and specificity was $83 \%$ and $89 \%$ for ER; $80 \%$ and $94 \%$ for PR; $63 \%$ and $89 \%$ for HER2 (by ICC); and 100\% and 92\% for HER2 (by FISH), respectively. The performance characteristics of the test support its suitability and adaptability for routine clinical use.
\end{abstract}

Keywords: Therapeutic biomarkers; circulating tumor cells; Immunocytochemistry; targeted therapy; Fluorescence in situ hybridization (FISH); Immune Checkpoint Inhibitors; Liquid Biopsy; Hormonal Treatments; Breast Cancer; Lung Cancer 


\section{Introduction}

Rapid advances in the understanding of key cellular pathways that drive cancer cell survival and proliferation have guided the development and use of molecularly targeted therapies in solid tumors. These molecular targets can be cell surface receptors or particular genetic alterations such as mutations, fusions or translocations that confer an oncogenic potential to cancer cells. Such anticancer agents act on specific molecular targets expressed preferentially by neoplastic cells, and therefore are expected to be more effective with fewer side effects than conventional cytotoxic anticancer treatments (chemotherapy) [1]. A wide range of targeted drugs have been approved by the US Food and Drug Administration and also recommended as standard of care therapies for multiple solid organ tumors. Immune checkpoint inhibitors Pembrolizumab, Nivolumab, Atezolizumab, Cemiplimab-rwlc, Ipilimumab for certain PD-L1 positive tumors; hormonal therapy such as Tamoxifen, Fulvestrant, Anastrozole, Letrozole, Exemestane targeting estrogen receptor (ER) in breast cancer; anti-HER2 drugs for HER2 overexpressing breast, colon, rectal, gastric and esophageal tumors are a few examples of targeted therapies in routine clinical use.

Accurate detection of the presence of these theranostic markers in tumor samples from cancer patients is the most crucial and ongoing need for directing the choice of targeted therapy for the patient. Programmed death-ligand 1 (PD-L1) expression in tumor tissue is a predictor for the efficacy of immune checkpoint inhibitors (ICIs) in some solid tumors. In addition to limitations inherent to tissue biopsy, predicting response to ICI therapy remains a challenge owing to variation in the choice of PD-L1 detection antibodies and relevant cell population, positivity cut-off values, sample processing, spatial and temporal heterogeneity in PD-L1 expression, and oncogenic versus induced PD-L1 expression [2-4].

Biomarker-guided systemic therapy in breast cancer is based on the several molecular subtypes of the disease determined by gene expression profiling and immunohistochemistry (IHC) analysis [5-9]. Discordance in tumor characteristics, predominantly the receptor status, of primary and metastatic breast cancer is largely due to tumor progression and evolution, the choice of adjuvant therapies and sites of metastasis [10-12]. As clinically relevant discordances in hormone receptor (ER, estrogen receptor; PR, progesterone receptor) and human epidermal growth factor receptor 2 (HER2) status impact prognosis, subsequent therapy choices and patient management [11,13-15], it warrants biopsy and retesting of the metastatic lesions for these markers [16-19]. However, biopsies of metastases or serial biopsies in case of disease progression are cumbersome, expensive, restricted to the most accessible metastatic site and do not account for intra-tumor and inter-metastatic heterogeneity. Such biopsies may also not be feasible or warranted due to poor ECOG performance score or co-morbidities.

CTC characterisation has the potential for non-invasive evaluation of these biomarkers for treatment selection as well as for longitudinal assessments to determine changes to biomarker status enabling predictive therapeutic course corrections [20-22]. We have previously demonstrated that CTCs are ubiquitous in various cancers, irrespective of radiological, metastatic or therapy status and can be utilized for non-invasive diagnostic triaging $[23,24]$. Here, we demonstrate the method development, optimization, analytical and clinical validation of a CTC based technology to evaluate therapeutically relevant targets viz. PD-L1, ER, PR and HER2 from blood samples of patients with solid organ cancers to guide choice of suitable targeted therapies. Figure 1 is a schema of the test showing the various steps in CTC enrichment followed by ICC/FISH profiling for therapeutic biomarkers.

\section{Materials and Methods}




\section{Samples}

All biological samples for the method development, optimization and validation were obtained from participants in two studies, TRUEBLOOD (CTRI/2019/03/017918; registered on 5th March, 2019) and RESOLUTE (CTRI/2019/01/017219; registered on 23rd January, 2019). Both studies, TRUEBLOOD (approved on 19th February, 2019) and RESOLUTE (approved on 1st January, 2019) were approved by Datar Cancer Genetics Limited Institutional Ethics Committee. The approval letters are available at:

http://ctri.nic.in/Clinicaltrials//WriteReadData/ethic/9337723928ECApprovalLetterTrueBloodAmendment.pdf

http://ctri.nic.in/Clinicaltrials//WriteReadData/ethic/6623151333ApprovalLetterbyEC-RESOLUTE.pdf

In addition, leftover blood samples from known (recently diagnosed or pre-treated) cancer patients who availed of Datar Cancer Genetics's commercial services for cancer management as well as healthy (asymptomatic) volunteers at the organization were also obtained. All participants provided written informed consent. Both studies were performed in accordance with the Declaration of Helsinki.

Peripheral blood mononuclear cells, Formalin-fixed, Paraffin-embedded (FFPE) tissue sections, cell lines and CTACs were used for FISH. Fresh tissue collected from all study participants was transported in transport medium or RNA later solution at $4^{\circ} \mathrm{C}$. FFPE tissue samples were transported to the laboratory at room temperature. All samples were processed at the DCGL Laboratory facility accredited by the College of American Pathologists (CAP) as well as Clinical Laboratory Improvement Amendments (CLIA).

Antisera and Cell Lines

The details of antisera and cell lines are provided in Supplementary Table S1. The purity of the cell lines was confirmed by Short Tandem Repeat (STR) Profiling and testing for Mycoplasma every 6 months.

Positive and Negative controls

The FISH assay included SKBR3 reference cell line as the positive control (with reported ERBB2 gene amplification) while peripheral blood mononuclear cells (PBMCs) isolated from asymptomatic individuals (males + females) with no history, suspicion or risk of cancer were used as negative control.

\section{Probe Design}

The CE IVD approved ZytoLight SPEC ERBB2/CEN 17 Dual Color Probe (PL8) was used for fluorescence in situ hybridization. The probe is a cocktail of ZyOrange (ex: 547 $\mathrm{nm}$, em: $572 \mathrm{~nm}$ ) labelled probe specific for the alpha satellite centromeric region of chromosome 17 (D17Z1, CEN17) and ZyGreen (ex: $503 \mathrm{~nm}$, em: $528 \mathrm{~nm}$ ) labelled probe specific for the chromosomal region 17q12-q21.1 harboring the ERBB2 gene.

Enrichment of Circulating Tumor Cells from Peripheral Blood

Aliquoted blood samples $(5 \mathrm{~mL})$ were processed for the enrichment of CTCs from peripheral blood mononuclear cells (PBMC) as described previously [25].

Immunocytochemistry Profiling of CTCs

The process of ICC profiling of CTCs was as described previously [24]. Representative fluorescent images of Circulating Tumor Cells (CTCs) isolated from cancer patient samples immuno-stained for A) PD-L1 22C3, B) PD-L1 28.8, C) ER, D) PR, and E) HER2 are provided in Supplementary Figure S4.

Fluorescence in situ hybridization (FISH)

Tissue sections were fixed on poly-L-Lysine coated slides for $1 \mathrm{~h}$ at $60{ }^{\circ} \mathrm{C}$ and then incubated at $70^{\circ} \mathrm{C}$ for $10 \mathrm{~min}$. Sections were dehydrated with serially diluted ethyl alcohol (increasing concentration), deparaffinized with 2 washes of xylene and finally rehydrated with serially diluted ethyl alcohol (decreasing concentration). Sections were preheated and then subjected to proteolysis with pepsin at $37^{\circ} \mathrm{C}$ for $35 \mathrm{~min}$. Following proteolysis, sections were washed with 1x saline sodium citrate (SSC) and dehydrated with serially diluted ethyl alcohol. DNA probe was carefully overlaid over tissue sections and covered with a coverslip. Denaturation was performed at $72{ }^{\circ} \mathrm{C}$ for $12 \mathrm{~min}$ followed by incubation 
in a humidified chamber for 17.5 hours. Post hybridization washing was performed twice for five minutes with wash buffer (manufacturer provided).

SKBR3 and PBMCs were diluted to $\sim 1000$ cells. CTACs with cell viability of $>90 \%$ and approximately 500-1000 cells per reaction were used. Cells were fixed with fresh 3:1 methanol: glacial acetic acid for $5 \mathrm{~min}$. Cells were harvested by centrifugation $(400 \times \mathrm{g}, 5 \mathrm{~min}$, room temperature) and resuspended in minimal diluent (as required for the number of assays). Slides were cleaned with $70 \%$ ethanol and coated with Poly-L-lysine before use. Approximately $10 \mu \mathrm{l}$ of the fixed cell suspension was placed on the slide. Freshly prepared 3: 1 methanol - acetic acid fixative was carefully overlaid on the cell suspension where a crater forms within the cell suspension. Additional fixative was overlaid dropwise until the aqueous solution drew back to the slide edges. The slide was then drained, dried and immersed in ice-cold methanol for 5 min. Fixed cells were treated with 2x SSC for 2 min followed by enzymatic proteolysis for $15 \mathrm{~min}$. Post fixation of the slides was performed using $1 \%$ formaldehyde solution for 5 min followed by washing for 15 min using $1 x$ Tris buffered saline (TBS) and dehydration using serially diluted ethanol. DNA probe was added onto the slide and covered with a coverslip. Denaturation was performed at $72{ }^{\circ} \mathrm{C}$ for $12 \mathrm{~min}$ followed by incubation in a humidified chamber for 17.5 hours. Post-hybridization washes $(2 x)$ were performed for $2 \mathrm{~min}$ with cytology stringency buffer and $5 \mathrm{~min}$ with cytology wash buffer SSC.

Finally, all slides (tissue / cells) were incubated with 4',6-diamidino-2-phenylindole (DAPI) for nuclear staining. Samples were then treated with antifade mountant for $15 \mathrm{~min}$ at room temperature. All slides were scanned on an Axio Imager Z2 (Carl Zeiss Oberkochen, Germany). Single color images were captured in several focus planes to capture both fluorophores. The reporting of all FISH samples was as per ASCO-CAP 2018 HER2 Testing Guidelines [26-28]. Representative fluorescent images of Circulating Tumor Cells (CTCs) and corresponding tumor tissue from a breast cancer patient positive for HER2 gene amplification (green) as evaluated by FISH is provided in Supplementary Figure S5.

IHC analysis

FFPE tissue was analyzed by IHC using Anti-Her-2 (Polyclonal, DAKO) as per standard procedures and the results were analyzed as per ASCO-CAP guidelines.

Method Development and Optimization - ICC

Details of method development and optimization studies as well as their findings are provided in the Supplementary Materials.

Analytical Validation - ICC

Details of extensive analytical validations which established the performance characteristics of the test as well as their findings are provided in the Supplementary Materials.

Analytical Validation - FISH

Analytical validation of the FISH process was performed using healthy donor PBMCs and ERBB2/CEN17 positive SKBR3 reference cells. Details are provided in Supplementary Materials and Supplementary Table S8.

\section{Clinical Study - ICC}

The ability of the test to detect theranostically relevant markers PD-L1, ER, PR and HER2 in the blood from cancer patients $(n=192)$ across 8 different solid organ tumors was ascertained and established. Further details are provided in Supplementary Tables S14 and S15.

Clinical Study - FISH

Clinical Validation of the test was established across 2 studies, with 54 known cases of breast cancer in study 1 and 44 cases in study 2, details of which are provided in Supplementary Materials.

\section{Results}

3.1. Analytical Validation - ICC 
The overall findings of the analytical validation study are presented in Table 1 . The detailed findings are provided in Supplementary Materials.

3.2 Analytical Validation - FISH

The detailed findings of the analytical validation of the FISH process are provided in Supplementary Materials.

3.3 Clinical Validation - ICC

We evaluated the performance characteristics of the test in a case control cross validation study. The study included sub-cohorts for PD-L1 22C3, PD-L1 28.8, ER, PR and HER2 where status of markers (positive or negative) was previously established via immunohistochemistry (IHC) of tumor tissue obtained by invasive biopsy. Samples were assigned to training and test sets in a 70\%:30\% ratio. Following initial assignment of samples into training and test sets, samples were shuffled and a random $30 \%$ selected successively to generate a total of 20 iterations of the test set. The performance characteristics of the test were evaluated across the 20 iterations of the test set; this cross validation model avoided anomalous results from overfitting (biased selection) as well as random enrichment (unbiased selection) of samples in the test set. Based on the cross validation, the median sensitivities for the markers as well as the best and worst case scenarios are presented in Table 2. The median sensitivity was 90\% for PD-L1 22C3, 90\% for PD-L1 28.8, $83 \%$ for ER, $80 \%$ for PR and $63 \%$ for HER2. The median specificity was $100 \%$ for PD-L1 22C3, 100\% for PD-L1 28.8, 89\% for ER, 94\% for PR and 89\% for HER2.

3.4 Clinical Validation - FISH

Clinical Validation of the test was established across 2 studies.

3.4.1 Study 1: The first study was a blinded case control study using CTACs from 54 known cases of breast cancer where ERBB2 gain (or its absence) was previously established on biopsied tumor tissue samples by FISH. This study employed a 20 -fold cross validation design to determine the sensitivity and the specificity.

Based on the cross validation, the median sensitivities for the markers as well as the best and worst case scenarios are presented in Table 2 and Supplementary Table S15 (HER2 FISH). The median sensitivity, specificity and accuracy was 100\%, 92\% and 94\% for ERBB2 on CTCs as evaluated by FISH.

3.4.2 Study 2: The second study was based on samples from 44 known cases of breast cancer. The samples in this study included a subset of samples from the first study as well as additional clinical samples which were not included in the first study. In the samples included in this study ERBB2 (HER2) status was previously established on tumor tissue by immunohistochemistry (IHC) as well as by FISH and on CTACs from matched blood samples collected from the same patients. The second study included samples where IHC of tumor tissue had indicated equivocal findings for HER2. This study established the concordance of tumor tissue-FISH as well as CTAC-FISH with tumor tissue- IHC

Among the 44 malignant samples where C-ETACs were analyzed, IHC indicated HER2 positivity in 10 samples, negative status in 25 samples and equivocal status in 9 samples. Among the HER2 positive samples, tissue FISH and CTAC FISH had sensitivities of $80 \%$ and $90 \%$ respectively. Among the HER2 negative samples tissue FISH and CTAC FISH had specificities of $100 \%$ and $96 \%$ respectively. Among the equivocal samples both tissue FISH and CTAC fish indicated positive status in the same 2 samples and negative status in the same 7 samples (Supplementary Table S16).

\subsection{Figures, Tables and Schemes}




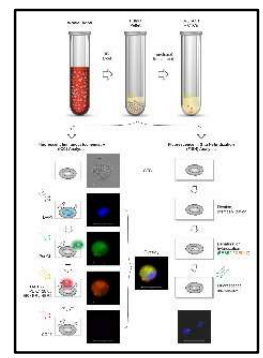

Figure 1. Schema of Test.

Functional enrichment of CTCs is achieved using an epigenetically activating medium that eliminates all non-malignant cells and permits tumor derived malignant cells to survive. Subsequently, the multiplexed immunocytochemistry (ICC) evaluates the presence of therapeutically relevant markers (PD-L1 22C3, PD-L1 28.8, ER, PR, and HER2) on respective CTCs. Fluorescence in situ hybridization (FISH) for HER2 assesses the amplification of this gene in enriched CTCs. The representative FISH image shows DAPI-stained nuclei of CTCs with HER2 gene amplification (green).

Table 1. Summary of Analytical Validation.

The findings of Analytical Validation indicate that the Test provides reliable, accurate and reproducible results when samples are obtained, stored and processed under the recommended conditions.

\begin{tabular}{|c|c|c|c|c|c|}
\hline & PD-L1 22C3 & PD-L1 28.8 & ER & PR & HER2 \\
\hline Analyte Stability & $24 \mathrm{~h}$ & $24 \mathrm{~h}$ & $24 \mathrm{~h}$ & $24 \mathrm{~h}$ & $24 \mathrm{~h}$ \\
\hline Recovery & $>85 \%$ & $>85 \%$ & $>85 \%$ & $>85 \%$ & $>85 \%$ \\
\hline Linearity & $>0.99$ & $>0.99$ & $>0.99$ & $>0.99$ & $>0.99$ \\
\hline Linear Range & $\begin{array}{c}7-1000 \text { cells / } 5 \\
\mathrm{~mL}\end{array}$ & $\begin{array}{c}7-1000 \text { cells / } 5 \\
\mathrm{~mL}\end{array}$ & $\begin{array}{c}5-1200 \text { cells / } 5 \\
\mathrm{~mL}\end{array}$ & $\begin{array}{c}5-1200 \text { cells / } 5 \\
\mathrm{~mL}\end{array}$ & $\begin{array}{c}5-1200 \text { cells / } 5 \\
\mathrm{~mL}\end{array}$ \\
\hline LoB & 0 cells / mL & 0 cells $/ \mathrm{mL}$ & 0 cells / mL & 0 cells $/ \mathrm{mL}$ & 0 cells / mL \\
\hline LoD & 2 cells $/ 5 \mathrm{~mL}$ & 2 cells / $5 \mathrm{~mL}$ & 3 cells / 5 mL & 3 cells / 5 mL & 3 cells / 5 mL \\
\hline LoQ & 7 cells / 5 mL & 7 cells / 5 mL & 5 cells / $5 \mathrm{~mL}$ & 5 cells / $5 \mathrm{~mL}$ & 5 cells / 5 mL \\
\hline Sensitivity & $\begin{array}{c}87.5 \% \\
(73.2 \%-95.81 \%)\end{array}$ & $\begin{array}{c}90 \% \\
(76.34 \%- \\
97.21 \%)\end{array}$ & $\begin{array}{c}87.5 \% \\
(73.2 \%-95.81 \%)\end{array}$ & $\begin{array}{c}95 \% \\
(83.08 \%- \\
99.39 \%)\end{array}$ & $\begin{array}{c}92.5 \% \\
(79.61 \%- \\
98.43 \%)\end{array}$ \\
\hline Specificity & $\begin{array}{c}100 \% \\
(86.28 \%-100 \%)\end{array}$ & $\begin{array}{c}100 \% \\
(86.28 \%-100 \%)\end{array}$ & $\begin{array}{c}100 \% \\
(86.28 \%-100 \%)\end{array}$ & $\begin{array}{c}100 \% \\
(86.28 \%-100 \%)\end{array}$ & $\begin{array}{c}100 \% \\
(86.28 \%-100 \%)\end{array}$ \\
\hline Accuracy & $\begin{array}{c}92.31 \% \\
(82.95 \%- \\
97.46 \%)\end{array}$ & $\begin{array}{c}93.85 \% \\
(84.99 \%- \\
98.30 \%)\end{array}$ & $\begin{array}{c}92.31 \% \\
(82.95 \%- \\
97.46 \%)\end{array}$ & $\begin{array}{c}96.92 \% \\
(89.32 \%- \\
99.63 \%)\end{array}$ & $\begin{array}{c}95.38 \% \\
(87.10 \%- \\
99.04 \%)\end{array}$ \\
\hline Precision & $\mathrm{CV} \leq 2.4 \%$ & $\mathrm{CV} \leq 2.4 \%$ & $\mathrm{CV} \leq 2.4 \%$ & $\mathrm{CV} \leq 2.4 \%$ & $\mathrm{CV} \leq 2.4 \%$ \\
\hline
\end{tabular}

Table 2. Clinical Performance Characteristics. 
The table provides the performance characteristics of the Test which were determined from 20 iterations of the Test Set and the Best-, Median- and Worst-Case values are reported.

\begin{tabular}{|c|c|c|c|c|}
\hline & & Sensitivity & Specificity & Accuracy \\
\hline \multirow{4}{*}{ 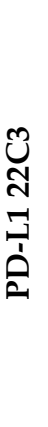 } & $\begin{array}{c}\text { Training } \\
\text { Set }\end{array}$ & $86 \%$ & $96 \%$ & $92 \%$ \\
\hline & $\begin{array}{l}\text { Test Set } \\
\text { (Worst) }\end{array}$ & $\begin{array}{c}70 \% \\
(50 \%-90 \%)\end{array}$ & $\begin{array}{c}100 \% \\
(100 \%-100 \%)\end{array}$ & $\begin{array}{c}86 \% \\
(71 \%-100 \%)\end{array}$ \\
\hline & $\begin{array}{l}\text { Test Set } \\
\text { (Median) }\end{array}$ & $\begin{array}{c}90 \% \\
(77 \%-100 \%) \\
\end{array}$ & $\begin{array}{c}100 \% \\
(100 \%-100 \%)\end{array}$ & $\begin{array}{c}95 \% \\
(86 \%-100 \%) \\
\end{array}$ \\
\hline & $\begin{array}{c}\text { Test Set } \\
\text { (Best) }\end{array}$ & $\begin{array}{c}100 \% \\
(100 \%-100 \%)\end{array}$ & $\begin{array}{c}100 \% \\
(100 \%-100 \%)\end{array}$ & $\begin{array}{c}100 \% \\
(100 \%-100 \%)\end{array}$ \\
\hline \multirow{4}{*}{ 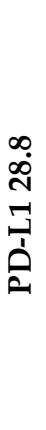 } & $\begin{array}{c}\text { Training } \\
\text { Set }\end{array}$ & $86 \%$ & $96 \%$ & $92 \%$ \\
\hline & $\begin{array}{l}\text { Test Set } \\
\text { (Worst) }\end{array}$ & $\begin{array}{c}70 \% \\
(50 \%-90 \%)\end{array}$ & $\begin{array}{c}91 \% \\
(79 \%-100 \%)\end{array}$ & $\begin{array}{c}86 \% \\
(71 \%-100 \%)\end{array}$ \\
\hline & $\begin{array}{l}\text { Test Set } \\
\text { (Median) }\end{array}$ & $\begin{array}{c}90 \% \\
(77 \%-100 \%)\end{array}$ & $\begin{array}{c}100 \% \\
(100 \%-100 \%)\end{array}$ & $\begin{array}{c}90 \% \\
(78 \%-100 \%)\end{array}$ \\
\hline & $\begin{array}{c}\text { Test Set } \\
\text { (Best) }\end{array}$ & $\begin{array}{c}100 \% \\
(100 \%-100 \%) \\
\end{array}$ & $\begin{array}{c}100 \% \\
(100 \%-100 \%) \\
\end{array}$ & $\begin{array}{c}100 \% \\
(100 \%-100 \%) \\
\end{array}$ \\
\hline \multirow{4}{*}{$\underset{r}{\check{I}}$} & $\begin{array}{l}\text { Training } \\
\text { Set }\end{array}$ & $83 \%$ & $94 \%$ & $88 \%$ \\
\hline & $\begin{array}{l}\text { Test Set } \\
\text { (Worst) }\end{array}$ & $\begin{array}{c}72 \% \\
(57 \%-88 \%)\end{array}$ & $\begin{array}{c}71 \% \\
(56 \%-87 \%)\end{array}$ & $\begin{array}{c}78 \% \\
(64 \%-92 \%)\end{array}$ \\
\hline & $\begin{array}{c}\text { Test Set } \\
\text { (Median) }\end{array}$ & $\begin{array}{c}83 \% \\
(70 \%-96 \%) \\
\end{array}$ & $\begin{array}{c}89 \% \\
(79 \%-100 \%) \\
\end{array}$ & $\begin{array}{c}84 \% \\
(72 \%-97 \%) \\
\end{array}$ \\
\hline & $\begin{array}{c}\text { Test Set } \\
\text { (Best) }\end{array}$ & $\begin{array}{c}94 \% \\
(87 \%-100 \%)\end{array}$ & $\begin{array}{c}100 \% \\
(100 \%-100 \%)\end{array}$ & $\begin{array}{c}94 \% \\
(85 \%-100 \%)\end{array}$ \\
\hline \multirow{4}{*}{$\stackrel{a}{a}$} & $\begin{array}{c}\text { Training } \\
\text { Set }\end{array}$ & $83 \%$ & $92 \%$ & $88 \%$ \\
\hline & $\begin{array}{l}\text { Test Set } \\
\text { (Worst) }\end{array}$ & $\begin{array}{c}60 \% \\
(43 \%-77 \%) \\
\end{array}$ & $\begin{array}{c}88 \% \\
(76 \%-99 \%) \\
\end{array}$ & $\begin{array}{c}77 \% \\
(63 \%-92 \%) \\
\end{array}$ \\
\hline & $\begin{array}{c}\text { Test Set } \\
\text { (Median) }\end{array}$ & $\begin{array}{c}80 \% \\
(66 \%-94 \%) \\
\end{array}$ & $\begin{array}{c}94 \% \\
(85 \%-100 \%) \\
\end{array}$ & $\begin{array}{c}87 \% \\
(75 \%-99 \%) \\
\end{array}$ \\
\hline & $\begin{array}{c}\text { Test Set } \\
\text { (Best) }\end{array}$ & $\begin{array}{c}93 \% \\
(85 \%-100 \%) \\
\end{array}$ & $\begin{array}{c}100 \% \\
(100 \%-100 \%)\end{array}$ & $\begin{array}{c}97 \% \\
(91 \%-100 \%) \\
\end{array}$ \\
\hline \multirow{4}{*}{ 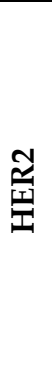 } & $\begin{array}{c}\text { Training } \\
\text { Set }\end{array}$ & $67 \%$ & $91 \%$ & $84 \%$ \\
\hline & $\begin{array}{l}\text { Test Set } \\
\text { (Worst) }\end{array}$ & $\begin{array}{c}38 \% \\
(19 \%-56 \%) \\
\end{array}$ & $\begin{array}{c}72 \% \\
(55 \%-89 \%) \\
\end{array}$ & $\begin{array}{c}69 \% \\
(51 \%-87 \%) \\
\end{array}$ \\
\hline & $\begin{array}{l}\text { Test Set } \\
\text { (Median) }\end{array}$ & $\begin{array}{c}63 \% \\
(44 \%-81 \%) \\
\end{array}$ & $\begin{array}{c}89 \% \\
(77 \%-100 \%) \\
\end{array}$ & $\begin{array}{c}79 \% \\
(63 \%-95 \%) \\
\end{array}$ \\
\hline & Test Set & $100 \%$ & $100 \%$ & $92 \%$ \\
\hline
\end{tabular}




\begin{tabular}{|c|c|c|c|c|}
\hline & & Sensitivity & Specificity & Accuracy \\
\hline & (Best) & $(100 \%-100 \%)$ & $(100 \%-100 \%)$ & $(82 \%-100 \%)$ \\
\hline \multirow{4}{*}{ 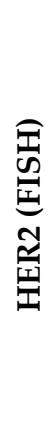 } & $\begin{array}{c}\text { Training } \\
\text { Set }\end{array}$ & $89 \%$ & $97 \%$ & $95 \%$ \\
\hline & $\begin{array}{l}\text { Test Set } \\
\text { (Worst) }\end{array}$ & $\begin{array}{c}75 \% \\
(54 \%-96 \%) \\
\end{array}$ & $\begin{array}{c}83 \% \\
(65 \%-100 \%)\end{array}$ & $\begin{array}{c}81 \% \\
(62 \%-100 \%)\end{array}$ \\
\hline & $\begin{array}{l}\text { Test Set } \\
\text { (Median) }\end{array}$ & $\begin{array}{c}100 \% \\
(100 \%-100 \%)\end{array}$ & $\begin{array}{c}92 \% \\
(78 \%-100 \%)\end{array}$ & $\begin{array}{c}94 \% \\
(82 \%-100 \%)\end{array}$ \\
\hline & $\begin{array}{c}\text { Test Set } \\
\text { (Best) }\end{array}$ & $\begin{array}{c}100 \% \\
(100 \%-100 \%)\end{array}$ & $\begin{array}{c}100 \% \\
(100 \%-100 \%)\end{array}$ & $\begin{array}{c}100 \% \\
(100 \%-100 \%)\end{array}$ \\
\hline
\end{tabular}

\section{Discussion}

We describe a non-invasive CTC-based assay for evaluation of therapeutically relevant biomarkers PD-L1, ER, PR and HER2 in blood samples from cancer patients with potential for clinical application in solid organ tumors. This test will be especially beneficial in cases where tissue insufficiency is encountered and / or an invasive tissue biopsy for tumor profiling is unviable. The test showed high analytical as well as clinical performance characteristics, which support its intended use for evaluation of target biomarkers for therapy selection.

Target biomarker expression is a prerequisite to identify cancer patients who are likely to benefit from targeted anticancer agents such as small molecules (e.g., TKI) or monoclonal antibodies (e.g., immune checkpoint inhibitors (ICI)). Although tumor tissue analysis by IHC remains the gold standard for most clinical molecular analysis for targeted therapy selection (with the exception of NGS for EGFR, BRAF or NTRK gene variants), it faces several biological and technological challenges. Liquid biopsy can be a viable alternative to tissue biopsy for determining expression of target biomarkers to guide therapy selection. Circulating tumor cells (CTCs), being the cells of tumorigenic origin in the bloodstream, represent an ideal biomarker for theranostic applications in cancer therapy [21]. Serial monitoring of tumor marker profile for monitoring dynamic alterations in marker status during disease progression or treatment is viable with CTCs which is not possible with tumor tissue. Changes in biomarker status have been previously reported in up to $42 \%$ of cases evaluated for either PD-L1, ER, PR or HER2 [29-35].

We have earlier demonstrated the clinical utility of circulating tumor cells enriched by this unique method, for screening, diagnostic triaging and non-invasive assessment of response to cytotoxic chemotherapy agents (CCA) in solid organ cancers [23-25]. In this study, we establish the clinical utility of CTCs obtained from patients with solid tumors in evaluating the therapeutically relevant targets, PD-L1, ER, PR and HER2 to guide choice of targeted therapies.

Targeting the immune checkpoint proteins (PD-L1 or PD-1) with inhibitory mABs is a treatment strategy in multiple cancers. The expression of PD-1 and PD-L1 proteins, is considered to be one of the factors predictive of response to ICI. IHC profiling of PD-L1 status is routinely used to identify patients likely to benefit from ICI therapies. Despite the reported value of assessing PD-L1 overexpression on cells of different types in solid tumors as a promising marker, its predictive value is restricted due to limitations of tumor tissue biopsy, dynamic expression profile of PD-L1, intratumoral heterogeneity as well as the influence of immune cell infiltrate in the tumor and its microenvironment [2,36]. Here, we demonstrate high specificity $(100 \%)$ and sensitivity $(90 \%)$ for both PD-L1 22C3 and PD-L1 28.8 antibody clones for detecting PD-L1 positive CTCs in patient samples. Although, the recommendation for ICI therapy based on our assay will be for cancer types 
as per standard guidelines and recommendations, owing to the nature of the analyte, we could eventually extend it to a tumor-agnostic setting.

Cheng et al. recently demonstrated the feasibility of CTC PD-L1 detection in peripheral blood using membrane filtration based on size [37]. Another study presented that PDL1 status in CTCs and circulating WBCs correlate with PD-L1 status in tumor tissue, revealing the potential of CTCs assessment as a non-invasive real-time biopsy to evaluate PD-L1 expression in patients with advanced-stage NSCLC [38]. Bergmann et al also evaluated the feasibility to detect CTC-PD-L1 expression in patients with advanced urothelial carcinoma using the CellSearch ${ }^{\circledR}$ system [39]. Although these studies have shown the feasibility and prognostic value of PD-L1 expression on CTCs, none of them have explored their therapeutic utility. A recent study by Choi et al on circulating tumor cell proportion scoring (CTPS) based PD-L1 assessment concluded that pure-CTCs based CTPS could be deployed for innovative diagnosis strategies as alternatives for tissue biopsy and to guide the personalized treatment in NSCLCs [40].

ER, PR and HER2 status is prognostic and predictive in breast cancer [41,42]. The choice of targeted therapies in breast, ovarian and uterine neoplasms depends on the expression of ER/PR on the tumor cells. Aromatase inhibitors Anastrozole, Letrozole, Exemestane; Estrogen receptor antagonists Tamoxifen and Fulvestrant are indicated for use in ER positive breast cancer. Aromatase inhibitors, Megestrol acetate, Medroxyprogesterone acetate and GnRH analogs are recommended for use in ER/PR-positive uterine sarcomas. HER2 positivity is associated with clinical benefit from anti-HER2 therapies in breast, colon, rectal, esophageal and gastric cancers. With our test, we show sensitivity of $83 \%$, $80 \%$ and $63 \%$ and specificity of $89 \%, 94 \%, 89 \%$ for ER, PR, HER2 respectively on CTCs derived from known cancer patients. Studies have reported significant heterogeneity between ER/PR/HER2 protein expression in CTCs and primary tumor/metastatic biopsy, and this status may change over time due to therapy [11,42-45]. In our CTC-based test, we observed slightly lower sensitivity for HER2 by ICC than other markers. However, we observed $100 \%$ median sensitivity and $92 \%$ specificity for HER2 as determined by FISH. Further, CTAC FISH had sensitivity of $90 \%$ among HER2 positive samples, and $96 \%$ specificity among HER2 negative samples with 100\% concordance with tissue-FISH for equivocal samples (Table 2, Supplementary Table S16).

The extent of discordance in marker status is varied across studies probably owing to different techniques used for evaluation of marker status. Clonal selection of minor subtype of cells "hidden" within the primary tumor following treatment, tumor heterogeneity, CTC selection process or inaccurate receptor status assessment of the primary tumor are speculated to be contributing factors for the observed discordance in tumor marker profile of primary tumor and CTCs [46,47]. A few studies elucidating the clinical relevance of this observation have been carried out. In the Treat CTC randomized phase II trial, patients with HER2 non-amplified breast cancer and $\geq 1$ centrally confirmed CTC/15 ml of blood were randomized (1:1) to Trastuzumab treatment. Trastuzumab did not decrease the detection rate of CTCs in HER2 non-amplified, non-metastatic breast cancer. However, as patients were eligible for this trial irrespective of CTCs HER2 status, the conclusions of this trial may not be directly relevant here [48]. The results of the randomized DETECT III trial suggested that Lapatinib resulted in early declines in circulating tumor cell counts (CTCs) in patients with initially HER2-negative metastatic breast cancer but HER2-positive CTCs [49]. Thus, it seems imperative to evaluate CTC based tumor marker status for personalised therapy guidance and monitoring.

Thus, evaluation of theranostic markers like PD-L1, ER, PR and HER2 on circulating tumor cells cannot only guide choice of targeted therapy, but also help stratify responders versus non-responders. The study, however, showed comparatively lower sensitivity (63\%) for detection of HER2 on CTCs by ICC and HER2 detection by FISH appears to be a more accurate option. Furthermore, this approach has not been prospectively evaluated for treatment response and patient survival where CTC profiling based treatment guidance was used for therapy selection. 
Overall, the study findings indicate that our assay for ICC characterisation of CTCs can substitute IHC analysis of tumor tissue for profiling of therapeutically relevant markers. This approach has application in cases where tumor tissue may be limited and / or where an invasive biopsy to obtain tumor tissue may be unviable as also where tumor evolution is suspected.

\section{Conclusions}

We describe a blood-based, non-invasive test which detects therapeutic biomarkers on CTCs with high sensitivity and specificity. The CTC based detection of PD-L1, ER, PR and HER2 markers offers a non-invasive alternative to tissue-based IHC for selection of immune-checkpoint inhibitors and targeted therapies for treatment of solid tumors. The test has the potential to accommodate spatial and temporal heterogeneity and is ideal for repeat sampling, longitudinal monitoring of tumor evolution and predictive therapeutic course corrections.

\section{Supplementary Materials: The supporting information can be downloaded at: www.mdpi.com/xxx/.}

Author Contributions: Conceptualization, Raymond Page, Darshana Patil, Dadasaheb Akolkar, Sudha Murthy, Pradeep Fulmali, Pooja Fulmali, Vineet Datta, Stefan Schuster and Rajan Datar; Data curation, Kiran Bendale, Revati Patil, Pradeep Fulmali, Pooja Fulmali, Archana Adhav, Sneha Puranik, Jinumary John and Ajay Srinivasan; Formal analysis, Dadasaheb Akolkar, Kiran Bendale, Revati Patil, Pradeep Fulmali, Pooja Fulmali, Archana Adhav, Sneha Puranik, Sachin Apurwa, Jinumary John and Ajay Srinivasan; Funding acquisition, Rajan Datar; Investigation, Dadasaheb Akolkar, Sudha Murthy, Kiran Bendale, Revati Patil, Pradeep Fulmali, Pooja Fulmali, Archana Adhav, Sneha Puranik and Chirantan Bose; Methodology, Raymond Page, Darshana Patil, Dadasaheb Akolkar, Sudha Murthy, Kiran Bendale, Revati Patil, Pradeep Fulmali, Pooja Fulmali, Archana Adhav, Sneha Puranik, Chirantan Bose, Jinumary John and Ajay Srinivasan; Project administration, Darshana Patil, Dadasaheb Akolkar, Pradeep Fulmali, Pooja Fulmali, Vineet Datta, Stefan Schuster and Rajan Datar; Resources, Dadasaheb Akolkar, Sudha Murthy, Vineet Datta, Chirantan Bose, Stefan Schuster and Rajan Datar; Software, Sachin Apurwa and Ajay Srinivasan; Supervision, Raymond Page, Darshana Patil, Dadasaheb Akolkar, Kiran Bendale, Revati Patil, Pradeep Fulmali, Pooja Fulmali, Ajay Srinivasan and Rajan Datar; Validation, Dadasaheb Akolkar, Kiran Bendale, Revati Patil, Pradeep Fulmali, Pooja Fulmali, Archana Adhav, Sneha Puranik and Sachin Apurwa; Visualization, Darshana Patil, Dadasaheb Akolkar, Pradeep Fulmali, Pooja Fulmali, Sachin Apurwa, Jinumary John, Ajay Srinivasan and Rajan Datar; Writing - original draft, Jinumary John and Ajay Srinivasan; Writing - review \& editing, Raymond Page, Darshana Patil, Dadasaheb Akolkar, Sudha Murthy, Vineet Datta, Stefan Schuster, Jinumary John, Ajay Srinivasan and Rajan Datar.

Funding: No external funding was obtained for this study. The entire study was funded by the Study Sponsor (DCG).

Data Availability Statement: The datasets and supplementary material generated during and/or analyzed during the current study are available from the corresponding author on reasonable request.

Acknowledgments: The authors are grateful towards all study participants and their caregivers. The contributions of the staff of the Study Sponsor (DCG) towards managing various clinical, operational and laboratory aspects of the study are also acknowledged with gratitude. The contributions of Harshal Bodke, Digambar Kotkar, Snehal Golar and Isha Pawar are also acknowledged.

Conflicts of Interest: RP, DP, DA, SM, KB, RP, PF, PF, AA, SP, SA, VD, CB, SS, JJ and AS are employees of the Study Sponsor; RD is the founder of the Study Sponsor. 
1. Talwar, V.; Pradeep Babu, K. V; Raina, S. An overall review of targeted therapy in solid cancers. Curr. Med. Res. Pract. 2017, 7, 99-105, doi:https://doi.org/10.1016/j.cmrp.2017.04.002.

2. Patel, S.P.; Kurzrock, R. PD-L1 Expression as a Predictive Biomarker in Cancer Immunotherapy. Mol. Cancer Ther. 2015, 14, 847-856, doi:10.1158/1535-7163.MCT-14-0983.

3. Madore, J.; Vilain, R.E.; Menzies, A.M.; Kakavand, H.; Wilmott, J.S.; Hyman, J.; Yearley, J.H.; Kefford, R.F.; Thompson, J.F.; Long, G. V; et al. PD-L1 expression in melanoma shows marked heterogeneity within and between patients: implications for anti-PD-1/PD-L1 clinical trials. Pigment Cell Melanoma Res. 2015, 28, 245-253, doi:10.1111/pcmr.12340.

4. $\quad$ Kerr, K.M.; Tsao, M.-S.; Nicholson, A.G.; Yatabe, Y.; Wistuba, I.I.; Hirsch, F.R. Programmed Death-Ligand 1 Immunohistochemistry in Lung Cancer: In what state is this art? J. Thorac. Oncol. Off. Publ. Int. Assoc. Study Lung Cancer 2015, 10, 985-989, doi:10.1097/JTO.0000000000000526.

5. Eroles, P.; Bosch, A.; Pérez-Fidalgo, J.A.; Lluch, A. Molecular biology in breast cancer: intrinsic subtypes and signaling pathways. Cancer Treat. Rev. 2012, 38, 698-707, doi:10.1016/j.ctrv.2011.11.005.

6. Nielsen, T.O.; Hsu, F.D.; Jensen, K.; Cheang, M.; Karaca, G.; Hu, Z.; Hernandez-Boussard, T.; Livasy, C.; Cowan, D.; Dressler, L.; et al. Immunohistochemical and clinical characterization of the basal-like subtype of invasive breast carcinoma. Clin. cancer Res. an Off. J. Am. Assoc. Cancer Res. 2004, 10, 5367-5374, doi:10.1158/1078-0432.CCR-04-0220.

7. Perou, C.M.; Sørlie, T.; Eisen, M.B.; van de Rijn, M.; Jeffrey, S.S.; Rees, C.A.; Pollack, J.R.; Ross, D.T.; Johnsen, H.; Akslen, L.A.; et al. Molecular portraits of human breast tumours. Nature 2000, 406, 747-752, doi:10.1038/35021093.

8. Sørlie, T.; Perou, C.M.; Tibshirani, R.; Aas, T.; Geisler, S.; Johnsen, H.; Hastie, T.; Eisen, M.B.; van de Rijn, M.; Jeffrey, S.S.; et al. Gene expression patterns of breast carcinomas distinguish tumor subclasses with clinical implications. Proc. Natl. Acad. Sci. U. S. A. 2001, 98, 10869-10874, doi:10.1073/pnas.191367098.

9. Park, S.; Koo, J.S.; Kim, M.S.; Park, H.S.; Lee, J.S.; Lee, J.S.; Kim, S. Il; Park, B.-W. Characteristics and outcomes according to molecular subtypes of breast cancer as classified by a panel of four biomarkers using immunohistochemistry. Breast 2012, 21, 50-57, doi:10.1016/j.breast.2011.07.008.

10. Lindström, L.S.; Karlsson, E.; Wilking, U.M.; Johansson, U.; Hartman, J.; Lidbrink, E.K.; Hatschek, T.; Skoog, L.; Bergh, J. Clinically used breast cancer markers such as estrogen receptor, progesterone receptor, and human epidermal growth factor receptor 2 are unstable throughout tumor progression. J. Clin. Oncol. Off. J. Am. Soc. Clin. Oncol. 2012, 30, 26012608, doi:10.1200/JCO.2011.37.2482.

11. Vogel, C.; Malter, W.; Morgenstern, B.; Ludwig, S.; Vehreschild, J.J.; Hamacher, S.; Mallmann, P.; Kirn, V.; Thangarajah, F. The Role of Previous Therapies and Sites of Metastasis as Influencing Factors on Discordance of ER, PR and HER2 Status Between Primary and Metastasized Breast Cancer. Anticancer Res. 2019, 39, 2647-2659, doi:10.21873/anticanres.13389.

12. Holzer, I.; Farr, A.; Tan, Y.; Deutschmann, C.; Leser, C.; Singer, C.F. Receptor Discordance of Metastatic Breast Cancer Depending on the Molecular Subtype. Breast Care (Basel). 2020, 15, 648-654, doi:10.1159/000506464.

13. Wilking, U.; Karlsson, E.; Skoog, L.; Hatschek, T.; Lidbrink, E.; Elmberger, G.; Johansson, H.; Lindström, L.; Bergh, J. HER2 status in a population-derived breast cancer cohort: discordances during tumor progression. Breast Cancer Res. Treat. 2011, 125, 553-561, doi:10.1007/s10549-010-1029-2.

14. Shin, H.-C.; Han, W.; Moon, H.-G.; Im, S.-A.; Moon, W.K.; Park, I.-A.; Park, S.J.; Noh, D.Y. Discordant ER, PR, and HER2 status between primary and metastatic breast cancer as prognostic factor. J. Clin. Oncol. 2013, 31, 1039, doi:10.1200/jco.2013.31.15\_suppl.1039.

15. Grinda, T.; Joyon, N.; Lusque, A.; Lefèvre, S.; Arnould, L.; Penault-Llorca, F.; Macgrogan, G.; Treilleux, I.; Vincent-Salomon, A.; Haudebourg, J.; et al. Phenotypic discordance between primary and metastatic breast cancer in the large-scale real-life multicenter French ESME cohort. NPJ breast cancer 2021, 7, 41, doi:10.1038/s41523-021-00252-6.

16. Cardoso, F.; Harbeck, N.; Fallowfield, L.; Kyriakides, S.; Senkus, E. Locally recurrent or metastatic breast cancer: ESMO 
Clinical Practice Guidelines for diagnosis, treatment and follow-up. Ann. Oncol. Off. J. Eur. Soc. Med. Oncol. 2012, 23 Suppl 7, vii11-9, doi:10.1093/annonc/mds232.

17. Amir, E.; Miller, N.; Geddie, W.; Freedman, O.; Kassam, F.; Simmons, C.; Oldfield, M.; Dranitsaris, G.; Tomlinson, G.; Laupacis, A.; et al. Prospective study evaluating the impact of tissue confirmation of metastatic disease in patients with breast cancer. J. Clin. Oncol. Off. J. Am. Soc. Clin. Oncol. 2012, 30, 587-592, doi:10.1200/JCO.2010.33.5232.

18. Van Poznak, C.; Somerfield, M.R.; Bast, R.C.; Cristofanilli, M.; Goetz, M.P.; Gonzalez-Angulo, A.M.; Hicks, D.G.; Hill, E.G.; Liu, M.C.; Lucas, W.; et al. Use of Biomarkers to Guide Decisions on Systemic Therapy for Women With Metastatic Breast Cancer: American Society of Clinical Oncology Clinical Practice Guideline. J. Clin. Oncol. Off. J. Am. Soc. Clin. Oncol. 2015, 33, 2695-2704, doi:10.1200/JCO.2015.61.1459.

19. NCCN Guidelines: Breast Cancer version 2.2022 Available online: https://www.nccn.org/professionals/physician_gls/pdf/breast.pdf (accessed on Jan 1, 2022).

20. Hegemann, M.; Stenzl, A.; Bedke, J.; Chi, K.N.; Black, P.C.; Todenhöfer, T. Liquid biopsy: ready to guide therapy in advanced prostate cancer? BJU Int. 2016, 118, 855-863, doi:10.1111/bju.13586.

21. Saarenheimo, J.; Eigeliene, N.; Andersen, H.; Tiirola, M.; Jekunen, A. The Value of Liquid Biopsies for Guiding Therapy Decisions in Non-small Cell Lung Cancer. Front. Oncol. 2019, 9, 129, doi:10.3389/fonc.2019.00129.

22. Guibert, N.; Pradines, A.; Favre, G.; Mazieres, J. Current and future applications of liquid biopsy in nonsmall cell lung cancer from early to advanced stages. Eur. Respir. Rev. an Off. J. Eur. Respir. Soc. 2020, 29, doi:10.1183/16000617.00522019.

23. Akolkar, D.; Patil, D.; Crook, T.; Limaye, S.; Page, R.; Datta, V.; Patil, R.; Sims, C.; Ranade, A.; Fulmali, P.; et al. Circulating ensembles of tumor-associated cells: A redoubtable new systemic hallmark of cancer. Int. J. cancer 2020, 146, 3485-3494, doi:10.1002/ijc.32815.

24. Gaya, A.; Crook, T.; Plowman, N.; Ranade, A.; Limaye, S.; Bhatt, A.; Page, R.; Patil, R.; Fulmali, P.; Datta, V.; et al. Evaluation of circulating tumor cell clusters for pan-cancer noninvasive diagnostic triaging. Cancer Cytopathol. 2021, 129, 226-238, doi:10.1002/cncy.22366.

25. Crook, T.; Gaya, A.; Page, R.; Limaye, S.; Ranade, A.; Bhatt, A.; Patil, S.; Kumar, P.; Patil, D.; Akolkar, D. Clinical utility of circulating tumor-associated cells to predict and monitor chemo-response in solid tumors. Cancer Chemother. Pharmacol. 2021, 87, 197-205, doi:10.1007/s00280-020-04189-8.

26. Wolff, A.C.; Hammond, M.E.H.; Allison, K.H.; Harvey, B.E.; Mangu, P.B.; Bartlett, J.M.S.; Bilous, M.; Ellis, I.O.; Fitzgibbons, P.; Hanna, W.; et al. Human Epidermal Growth Factor Receptor 2 Testing in Breast Cancer: American Society of Clinical Oncology/College of American Pathologists Clinical Practice Guideline Focused Update. Arch. Pathol. Lab. Med. 2018, 142, 1364-1382, doi:10.5858/arpa.2018-0902-SA.

27. Valtorta, E.; Martino, C.; Sartore-Bianchi, A.; Penaullt-Llorca, F.; Viale, G.; Risio, M.; Rugge, M.; Grigioni, W.; Bencardino, K.; Lonardi, S.; et al. Assessment of a HER2 scoring system for colorectal cancer: results from a validation study. Mod. Pathol. an Off. J. United States Can. Acad. Pathol. Inc 2015, 28, 1481-1491, doi:10.1038/modpathol.2015.98.

28. Sartore-Bianchi, A.; Trusolino, L.; Martino, C.; Bencardino, K.; Lonardi, S.; Bergamo, F.; Zagonel, V.; Leone, F.; Depetris, I.; Martinelli, E.; et al. Dual-targeted therapy with trastuzumab and lapatinib in treatment-refractory, KRAS codon 12/13 wild-type, HER2-positive metastatic colorectal cancer (HERACLES): a proof-of-concept, multicentre, open-label, phase 2 trial. Lancet. Oncol. 2016, 17, 738-746, doi:10.1016/S1470-2045(16)00150-9.

29. Peng, L.; Zhang, Z.; Zhao, D.; Zhao, J.; Mao, F.; Sun, Q. Discordance in ER, PR, HER2, and Ki-67 Expression Between Primary and Recurrent/Metastatic Lesions in Patients with Primary Early Stage Breast Cancer and the Clinical Significance: Retrospective Analysis of 75 Cases. Pathol. Oncol. Res. 2021, 27, 599894, doi:10.3389/pore.2021.599894.

30. Curtit, E.; Nerich, V.; Mansi, L.; Chaigneau, L.; Cals, L.; Villanueva, C.; Bazan, F.; Montcuquet, P.; Meneveau, N.; Perrin, S.; et al. Discordances in estrogen receptor status, progesterone receptor status, and HER2 status between primary breast 
cancer and metastasis. Oncologist 2013, 18, 667-674, doi:10.1634/theoncologist.2012-0350.

31. Yao, Z.-X.; Lu, L.-J.; Wang, R.-J.; Jin, L.-B.; Liu, S.-C.; Li, H.-Y.; Ren, G.-S.; Wu, K.-N.; Wang, D.-L.; Kong, L.-Q. Discordance and clinical significance of ER, PR, and HER2 status between primary breast cancer and synchronous axillary lymph node metastasis. Med. Oncol. 2014, 31, 798, doi:10.1007/s12032-013-0798-y.

32. Lower, E.E.; Khan, S.; Kennedy, D.; Baughman, R.P. Discordance of the estrogen receptor and HER-2/neu in breast cancer from primary lesion to first and second metastatic site. Breast cancer (Dove Med. Press. 2017, 9, 515-520, doi:10.2147/BCTT.S137709.

33. Manson, Q.F.; Schrijver, W.A.M.E.; Ter Hoeve, N.D.; Moelans, C.B.; van Diest, P.J. Frequent discordance in PD-1 and PD-L1 expression between primary breast tumors and their matched distant metastases. Clin. Exp. Metastasis 2019, 36, 29-37, doi:10.1007/s10585-018-9950-6.

34. Boman, C.; Zerdes, I.; Mårtensson, K.; Bergh, J.; Foukakis, T.; Valachis, A.; Matikas, A. Discordance of PD-L1 status between primary and metastatic breast cancer: A systematic review and meta-analysis. Cancer Treat. Rev. 2021, 99, 102257, doi:10.1016/j.ctrv.2021.102257.

35. Naso, J.R.; Banyi, N.; Al-Hashami, Z.; Zhu, J.; Wang, G.; Ionescu, D.N.; Ho, C. Discordance in PD-L1 scores on repeat testing of non-small cell lung carcinomas. Cancer Treat. Res. Commun. 2021, 27, 100353, doi:10.1016/j.ctarc.2021.100353.

36. Kloten, V.; Lampignano, R.; Krahn, T.; Schlange, T. Circulating Tumor Cell PD-L1 Expression as Biomarker for Therapeutic Efficacy of Immune Checkpoint Inhibition in NSCLC. Cells 2019, 8, doi:10.3390/cells8080809.

37. Cheng, Y.; Wang, T.; Lv, X.; Li, R.; Yuan, L.; Shen, J.; Li, Y.; Yan, T.; Liu, B.; Wang, L. Detection of PD-L1 Expression and Its Clinical Significance in Circulating Tumor Cells from Patients with Non-Small-Cell Lung Cancer. Cancer Manag. Res. 2020, 12, 2069-2078, doi:10.2147/CMAR.S245425.

38. Ilié, M.; Szafer-Glusman, E.; Hofman, V.; Chamorey, E.; Lalvée, S.; Selva, E.; Leroy, S.; Marquette, C.-H.; Kowanetz, M.; Hedge, P.; et al. Detection of PD-L1 in circulating tumor cells and white blood cells from patients with advanced nonsmall-cell lung cancer. Ann. Oncol. Off. J. Eur. Soc. Med. Oncol. 2018, 29, 193-199, doi:10.1093/annonc/mdx636.

39. Bergmann, S.; Coym, A.; Ott, L.; Soave, A.; Rink, M.; Janning, M.; Stoupiec, M.; Coith, C.; Peine, S.; von Amsberg, G.; et al. Evaluation of PD-L1 expression on circulating tumor cells (CTCs) in patients with advanced urothelial carcinoma (UC). Oncoimmunology 2020, 9, 1738798, doi:10.1080/2162402X.2020.1738798.

40. Choi, M.Y.; Moon, D.H.; Jo, J.; Lee, H.U.; Park, S.; Jeon, B.H.; Choi, C.M. Circulating tumor cell proportion scoring (CTPS) based PD-L1 assessment and clinical application of circulating tumor cells (CTCs) on stage IV non-small cell lung cancer (NSCLC) through liquid biopsy. J. Clin. Oncol. 2021, 39, e15031-e15031, doi:10.1200/JCO.2021.39.15\_suppl.e15031.

41. Kalinsky, K.; Mayer, J.A.; Xu, X.; Pham, T.; Wong, K.L.; Villarin, E.; Pircher, T.J.; Brown, M.; Maurer, M.A.; Bischoff, F.Z. Correlation of hormone receptor status between circulating tumor cells, primary tumor, and metastasis in breast cancer patients. Clin. Transl. Oncol. Off. Publ. Fed. Spanish Oncol. Soc. Natl. Cancer Inst. Mex. 2015, 17, 539-546, doi:10.1007/s12094-015-1275-1.

42. Müller, V.; Banys-Paluchowski, M.; Friedl, T.W.P.; Fasching, P.A.; Schneeweiss, A.; Hartkopf, A.; Wallwiener, D.; Rack, B.; Meier-Stiegen, F.; Huober, J.; et al. Prognostic relevance of the HER2 status of circulating tumor cells in metastatic breast cancer patients screened for participation in the DETECT study program. ESMO open 2021, 6, 100299, doi:10.1016/j.esmoop.2021.100299.

43. Flores, L.M.; Kindelberger, D.W.; Ligon, A.H.; Capelletti, M.; Fiorentino, M.; Loda, M.; Cibas, E.S.; Jänne, P.A.; Krop, I.E. Improving the yield of circulating tumour cells facilitates molecular characterisation and recognition of discordant HER2 amplification in breast cancer. Br. J. Cancer 2010, 102, 1495-1502, doi:10.1038/sj.bjc.6605676.

44. Bischoff, F.Z.; Pircher, T.J.; Pham, T.; Wong, K.; Villarin, E.; Kalinsky, K.; Mayer, J.A. Immunocytochemistry staining for ER and PR in circulating tumor cells as compared to primary tumor or metastatic biopsy. J. Clin. Oncol. 2012, 30, 584,

doi:10.1200/jco.2012.30.15\_suppl.584. 
45. Aktas, B.; Kasimir-Bauer, S.; Müller, V.; Janni, W.; Fehm, T.; Wallwiener, D.; Pantel, K.; Tewes, M. Comparison of the HER2, estrogen and progesterone receptor expression profile of primary tumor, metastases and circulating tumor cells in metastatic breast cancer patients. BMC Cancer 2016, 16, 522, doi:10.1186/s12885-016-2587-4.

46. Krishnamurthy, S.; Bischoff, F.; Ann Mayer, J.; Wong, K.; Pham, T.; Kuerer, H.; Lodhi, A.; Bhattacharyya, A.; Hall, C.; Lucci, A. Discordance in HER2 gene amplification in circulating and disseminated tumor cells in patients with operable breast cancer. Cancer Med. 2013, 2, 226-233, doi:10.1002/cam4.70.

47. De Gregorio, A.; Friedl, T.W.P.; Huober, J.; Scholz, C.; De Gregorio, N.; Rack, B.; Trapp, E.; Alunni-Fabbroni, M.; Riethdorf, S.; Mueller, V.; et al. Discordance in Human Epidermal Growth Factor Receptor 2 (HER2) Phenotype Between Primary Tumor and Circulating Tumor Cells in Women With HER2-Negative Metastatic Breast Cancer. JCO Precis. Oncol. 2017, 112, doi:10.1200/PO.17.00023.

48. Ignatiadis, M.; Litière, S.; Rothe, F.; Riethdorf, S.; Proudhon, C.; Fehm, T.; Aalders, K.; Forstbauer, H.; Fasching, P.A.; Brain, E.; et al. Trastuzumab versus observation for HER2 nonamplified early breast cancer with circulating tumor cells (EORTC 90091-10093, BIG 1-12, Treat CTC): a randomized phase II trial. Ann. Oncol. Off. J. Eur. Soc. Med. Oncol. 2018, 29, 17771783, doi:10.1093/annonc/mdy211.

49. Fehm, T.; Müller, V.; Banys-Paluchowski, M.; Fasching, P.; Friedl, T.; Hartkopf, A.; Huober, J.; Loehberg, C.; Rack, B.; Riethdorf, S.; et al. Abstract PD3-12: Efficacy of the tyrosine kinase inhibitor lapatinib in the treatment of patients with HER2negative metastatic breast cancer and HER2-positive circulating tumor cells - results from the randomized phase III DETECT III trial; 2021; 